\title{
DEVELOPMENT AND VALIDATION OF STABILITY INDICATING SIMULTANEOUS UV- SPECTROPHOTOMETRIC METHOD FOR DETERMINATION OF EMTRICITABINE, TENOFOVIR DISOPROXIL FUMARATE, COBICISTAT, AND ELVITEGRAVIR IN PURE AND PHARMACEUTICAL DOSAGE FORM
}

\author{
HARINI U*, PAWAR AKM \\ Department of Pharmaceutical Analysis and Quality Assurance, University College of Pharmaceutical Sciences, Andhra University, \\ Visakhapatnam, Andhra Pradesh, India. Email: hariniuppada413@gmail.com \\ Received: 04 December 2017, Revised and Accepted: 01 January 2018
}

\begin{abstract}
Objective: The objective of this research work was to develop and validate a simple, precise, and accurate new ultraviolet-spectrophotometric method for the simultaneous estimation of emtricitabine (EMT), tenofovir disoproxil fumarate (TDF), cobicistat (COB), and elvitegravir (ELV) in pure and pharmaceutical marketed dosage form (stribild).
\end{abstract}

Methods: Simultaneous equation method (Vierordt's method) was developed for simultaneous determination of several mixtures containing two or more absorbing drugs (p, q, r, and s) each of which absorbs at the $\lambda$ max of the other. Forced degradation studies were also conducted, and the drugs were subjected to various stress conditions such as acid hydrolysis, base hydrolysis, oxidative, photolytic, and thermal degradation.

Results: The $\lambda$ max of EMT, ten TDF, COB, and ELV are $283 \mathrm{~nm}, 259 \mathrm{~nm}, 240 \mathrm{~nm}$, and $258 \mathrm{~nm}$, respectively. The linearity ranges for the four drugs are EMT (4-24 $\mu \mathrm{g} / \mathrm{ml})$, TDF (10-50 $\mu \mathrm{g} / \mathrm{ml})$, COB (10-120 $\mu \mathrm{g} / \mathrm{ml})$, and ELV $(2-10 \mu \mathrm{g} / \mathrm{ml})$.

Conclusion: The Vierordt's method was successfully applied for simultaneous determination of EMT, TDF, COB, and ELV in a mixture of sample solution (pharmaceutical dosage form) and the results obtained were validated and found to be accurate, precise, linear, rugged, and robust.

Keywords: Vierordt's method, Emtricitabine, Tenofovir disoproxil fumarate, Cobicistat, Elvitegravir.

(C) 2018 The Authors. Published by Innovare Academic Sciences Pvt Ltd. This is an open access article under the CC BY license (http://creativecommons. org/licenses/by/4. 0/) DOI: http://dx.doi.org/10.22159/ajpcr.2018.v11i4.22897

\section{INTRODUCTION}

The human immunodeficiency virus (HIV) is a lentivirus (a subgroup of retroviruses) that causes HIV infection and over time acquired immunodeficiency syndrome (AIDS). AIDS is a condition in humans in which progressive failure of the immune system allows life-threatening infections and cancers. Stribild, the first integrase inhibitor-based single tablet regimen containing emtricitabine (EMT), tenofovir disoproxil fumarate (TDF), cobicistat (COB), and elvitegravir (ELV) for HIV-1 infection, meets current $\mathrm{WHO}$ treatment guidelines for a complete fixed-dose, once daily highly active antiretroviral therapy (HAART) regimens. HAART is the name given to aggressive treatment regimens used to suppress HIV viral replication and the progression of HIV disease. Stribild is a pill combination of four active ingredients- $150 \mathrm{mg}$ of ELV, $150 \mathrm{mg}$ of COB, $200 \mathrm{mg}$ of EMT, and $300 \mathrm{mg}$ of TDF (equivalent to $245 \mathrm{mg}$ of tenofovir disoproxil) and is taken once a day [1-5].

\section{EMT}

The chemical name of EMT is 6-(3-chloro-2-fluorobenzyl)-1-([2S]-1 hydroxy-3-methylbutan-2-yl)-7-methoxy-4-oxo-1, 4-dihydroquinoline3 -carboxylic acid. EMT is the (-) enantiomer of a thio analog of cytidine, which differs from other cytidine analogs in that it has a fluorine in the 5-position. EMT is a nucleoside reverse transcriptase inhibitor (NRTI) for the treatment of HIV infection in adults. It has a molecular formula of $\mathrm{C}_{8} \mathrm{H}_{10} \mathrm{FN}_{3} \mathrm{O}_{3} \mathrm{~S}$ and a molecular weight of 247.25 . It is a white to offwhite crystalline powder with a solubility of approximately $112 \mathrm{mg} / \mathrm{ml}$ in water at $25^{\circ} \mathrm{C}$. It has the following structural formula (Fig. 1).

TDF

TDF is a fumaric acid salt of the bis-isopropoxy carbonyl oxy methyl ester derivative of tenofovir. The chemical name of TDF is 9-[(R)-2- [[bis [[(isopropoxy carbonyl) oxy] methoxy] phosphinyl] methoxy] propyl] adenine fumarate. TDF belongs to a class of antiretroviral drugs known as nucleotide analog reverse transcriptase inhibitors NRTIs. It has a molecular formula of $\mathrm{C}_{19} \mathrm{H}_{30} \mathrm{~N}_{5} \mathrm{O}_{10} \mathrm{P} \mathrm{C}_{4} \mathrm{H}_{4} \mathrm{O}_{4}$ and a molecular weight of 635.51. It is a white to off-white crystalline powder with a solubility of $13.4 \mathrm{mg} / \mathrm{ml}$ in water at $25^{\circ} \mathrm{C}$. It has the following structural formula (Fig. 2).

\section{COB}

The chemical name for СOB is 1, 3-thiazol-5-ylmethyl [(2R,5R)5-\{[(2S)-2- [(methyl \{[2-(propan-2-yl)-1,3-thiazol-4-yl] methyl $\}$ carbamoyl) amino]-4 (morpholin-4-yl) butanol] amino\}-1,6-diphenyl hexan-2-yl] carbamate. COB acts as an HIV integrase inhibitor. COB is the only other booster approved for use as a part of HAART, COB has no anti-HIV activity of its own. COB is a potent inhibitor of cytochrome p450 3A enzymes, including the important CYP3A4 subtype. It also inhibits intestinal transport proteins, increasing the overall absorption of several HIV medications. It has a molecular formula of $\mathrm{C}_{40} \mathrm{H}_{53} \mathrm{~N}_{7} \mathrm{O}_{5} \mathrm{~S}_{2}$ and a molecular weight of 776.0. It is adsorbed onto silicon dioxide. $\mathrm{COB}$ on silicon dioxide is a white to pale yellow solid with a solubility of $0.1 \mathrm{mg} / \mathrm{ml}$ in water at $20^{\circ} \mathrm{C}$. It has the following structural formula (Fig. 3).

\section{ELV}

The chemical name of ELV is 6-(3-chloro-2-fluorobenzyl)-1[(2S)-1hydroxy-3-methylbutan-2-yl]-7-methoxy-4-oxo-1,4dihydroquinoline-3-carboxylic acid. ELV is a drug used for the treatment of HIV infection. It acts as an integrase inhibitor. It has a molecular formula of $\mathrm{C}_{23} \mathrm{H}_{23} \mathrm{ClFNO}_{5}$ and a molecular weight of 447.9. ELV is a white to pale yellow powder with a solubility of $<0.3 \mu \mathrm{g} / \mathrm{ml}$ in water at $20^{\circ} \mathrm{C}$. 
It has the following structural formula (Fig. 4).

Literature survey reveals that there are very few ultraviolet (UV) spectrophotometric methods available for the estimation of EMT, TDF, $\mathrm{COB}$, and ELV individually, but there is no UV method for simultaneous estimation of this quad pill. Hence, there is a need to develop and validate a new UV spectrophotometric method for simultaneous estimation of EMT, TDF, COB, and ELV in pure and pharmaceutical dosage form [6-14].

\section{EXPERIMENT}

\section{Apparatus}

Lab India-T60 UV/visible double beam spectrophotometer with a spectral bandwidth of $1 \mathrm{~nm}$ and $1.0 \mathrm{~cm}$ matched quartz cells was used for UV spectrophotometry. The software used for data acquisition was UV win, and Mettler Toledo ME 204 weighing balance was used.

\section{Chemicals}

EMT, TDF, COB, ELV reference standards, and stribild marketed formulation tablets were kindly given as gift samples. AR Grade methanol (Thermo Fisher Scientific Indian Pvt. Ltd. Mumbai, India) and double distilled water were used to prepare all solutions and cleaning glassware.

\section{Selection of solvent and detection wavelength}

All the four drugs EMT, TDF, COB, and ELV were freely soluble in methanol, and moreover, the drug showed higher absorbance in methanol and, hence, methanol was used as a solvent for preparation of solutions. Drug solutions of $10 \mu \mathrm{g} / \mathrm{ml}$ were prepared for the four pure drugs and scanned over the range of 200-400 $\mathrm{nm}$ in UV/visible spectrophotometer using methanol as blank. The $\lambda$ max of EMT, TDF, COB, and ELV was found at $283 \mathrm{~nm}, 259 \mathrm{~nm}, 240 \mathrm{~nm}$, and $258 \mathrm{~nm}$, respectively. The UV spectrum obtained are shown in Figs. 5-9.

\section{METHOD}

Simultaneous equation method (Vierordt's method)

Four wavelengths required in this method were selected at which one component shows maximum absorbance while remaining shows considerable absorbance. Considering this fact, wavelengths $283 \mathrm{~nm}$, $259 \mathrm{~nm}, 240 \mathrm{~nm}$, and $258 \mathrm{~nm}$ ( $\lambda$ max of all four drugs) were selected for the estimation of EMT, TDF, COB, and ELV by simultaneous equation method. At all selected wavelengths, the absorbance and absorptivity values of four drugs were determined as follows. The absorptivity of each solution was calculated using the following formula:

Absorptivity $=\frac{\text { Absorbance }}{\text { Concentration }(\mathrm{gm} / 100 \mathrm{~mL})}$

$\mathrm{A}_{1}=\mathrm{a}_{\mathrm{p}^{1}} \mathrm{bc} \mathrm{p}_{\mathrm{p}}+\mathrm{a}_{\mathrm{q}^{1}} \mathrm{bc} \mathrm{q}_{\mathrm{q}}+\mathrm{a}_{\mathrm{r}^{1}} \mathrm{bc}_{\mathrm{r}}+\mathrm{a}_{\mathrm{s}^{1}} \mathrm{bc} \mathrm{c}_{\mathrm{s}}$

$A_{2}=a_{p^{2}} b c_{p}+a_{q^{2}} b c_{q}+a_{r^{2}} b c_{r}+a_{s^{2}} b c_{s}$

$283 \mathrm{~nm}$

$A_{3}=a_{p^{3}} b c_{p}+a_{q^{3}} b c_{q}+a_{r^{3}} b c_{r}+a_{s^{3}} b c_{s}$

$259 \mathrm{~nm}$

$A_{4}=a_{p^{4}} b c_{p}+a_{q^{4}} b c_{q}+a_{r^{4}} b c_{r}+a_{s^{4}} b c_{s}$

$240 \mathrm{~nm}$

$258 \mathrm{~nm}$

For measurements in $1 \mathrm{~cm}$ cell $\mathrm{b}=1$. Hence

$\left[\begin{array}{cccc}a_{p^{1}} & a_{q^{1}} & a_{r^{1}} & a_{s^{1}} \\ a_{p^{2}} & a_{q^{2}} & a_{r^{2}} & a_{s^{2}} \\ a_{p^{3}} & a_{q^{3}} & a_{r^{3}} & a_{s^{3}} \\ a_{p^{4}} & a_{q^{4}} & a_{r^{4}} & a_{s^{4}}\end{array}\right]\left[\begin{array}{c}c_{p} \\ c_{q} \\ c_{r} \\ c_{s}\end{array}\right]=\left[\begin{array}{c}A_{1} \\ A_{2} \\ A_{3} \\ A_{4}\end{array}\right]$

Apply the Cramer's rule for above equations.
$\operatorname{Det}(D)=\left|\begin{array}{cccc}a_{p^{1}} & a_{q^{1}} & a_{r^{1}} & a_{s^{1}} \\ a_{p^{2}} & a_{q^{2}} & a_{r^{2}} & a_{s^{2}} \\ a_{p^{3}} & a_{q^{3}} & a_{r^{3}} & a_{s^{3}} \\ a_{p^{4}} & a_{q^{4}} & a_{q^{4}} & a_{s^{4}}\end{array}\right|$

$D_{c_{p}}=\left|\begin{array}{cccc}A_{1} & a_{q^{1}} & a_{r^{1}} & a_{s^{1}} \\ A_{2} & a_{q^{2}} & a_{r^{2}} & a_{s^{2}} \\ A_{3} & a_{q^{3}} & a_{r^{3}} & a_{s^{3}} \\ A_{4} & a_{q^{4}} & a_{q^{4}} & a_{s^{4}}\end{array}\right|$

$D_{c_{q}}=\left|\begin{array}{cccc}a_{p^{1}} & A_{1} & a_{r^{1}} & a_{s^{1}} \\ a_{p^{2}} & A_{2} & a_{r^{2}} & a_{s^{2}} \\ a_{p^{3}} & A_{3} & a_{r^{3}} & a_{s^{3}} \\ a_{p^{4}} & A_{4} & a_{q^{4}} & a_{s^{4}}\end{array}\right|$

$D_{c_{r}}=\left|\begin{array}{cccc}a_{p^{1}} & a_{q^{1}} & A_{1} & a_{s^{1}} \\ a_{p^{2}} & a_{q^{2}} & A_{2} & a_{s^{2}} \\ a_{p^{3}} & a_{q^{3}} & A_{3} & a_{s^{3}} \\ a_{p^{4}} & a_{q^{4}} & A_{4} & a_{s^{4}}\end{array}\right| \quad D_{c_{s}}=\left|\begin{array}{cccc}a_{p^{1}} & a_{q^{1}} & a_{r^{1}} & A_{1} \\ a_{p^{2}} & a_{q^{2}} & a_{r^{2}} & A_{2} \\ a_{p^{3}} & a_{q^{3}} & a_{r^{3}} & A_{3} \\ a_{p^{4}} & a_{q^{4}} & a_{q^{4}} & A_{4}\end{array}\right|$

$c_{p}=\frac{D_{c_{p}}}{D}$

1

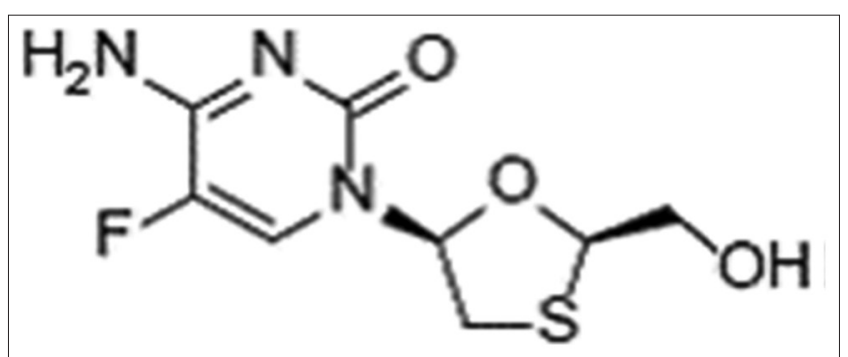

Fig. 1: Structure of emtricitabine

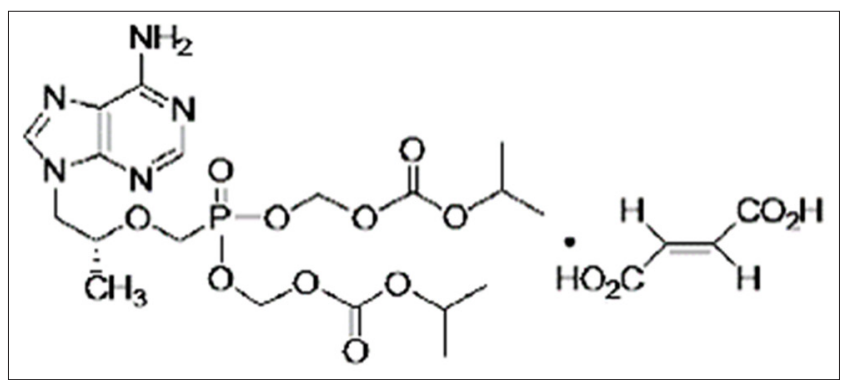

Fig. 2: Structure of tenofovir disoproxil fumarate

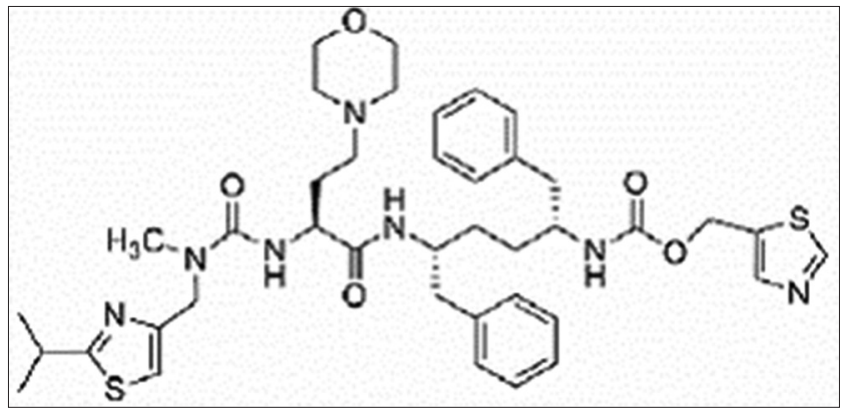

Fig. 3: Structure of cobicistat 
$c_{q}=\frac{D_{c_{q}}}{D}$

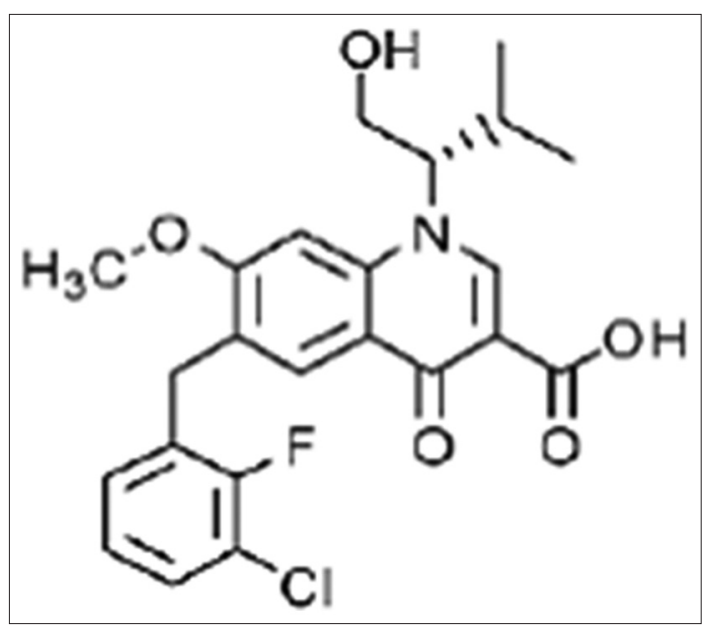

Fig. 4: Structure of elvitegravir
$c_{r}=\frac{D_{c_{r}}}{D}$

$\mathrm{c}_{\mathrm{S}}=\frac{\mathrm{D}_{\mathrm{c}_{\mathrm{s}}}}{\mathrm{D}}$

The absorbance of the mixture at $283 \mathrm{~nm}, 259 \mathrm{~nm}, 240 \mathrm{~nm}$, and $258 \mathrm{~nm}$ may be expressed as $\mathrm{A}_{1}, \mathrm{~A}_{2}, \mathrm{~A}_{3}$, and $\mathrm{A}_{4}$. The absorptivity of EMT at $283 \mathrm{~nm}$, $259 \mathrm{~nm}, 240 \mathrm{~nm}$, and $258 \mathrm{~nm}$ is ap ${ }_{1}, \mathrm{ap}_{2}, \mathrm{ap}_{3}$, and ap $\mathrm{p}_{4}$, respectively. The absorptivity of tenofovir at $283 \mathrm{~nm}, 259 \mathrm{~nm}, 240 \mathrm{~nm}$, and $258 \mathrm{~nm}$ is $\mathrm{aq}_{1}, \mathrm{aq}_{2}, \mathrm{aq}_{3}$, and $\mathrm{aq}_{4}$, respectively. The absorptivity of COB at $283 \mathrm{~nm}$, $259 \mathrm{~nm}, 240 \mathrm{~nm}$, and $258 \mathrm{~nm}$ is $\mathrm{ar}_{1}, \mathrm{ar}_{2}, \mathrm{ar}_{3}$, and $\mathrm{ar}_{4}$, respectively. The absorptivity of ELV at $283 \mathrm{~nm}, 259 \mathrm{~nm}, 240 \mathrm{~nm}$, and $258 \mathrm{~nm}$ is as ${ }_{1}$, as ${ }_{2}$, $\mathrm{as}_{3}$, and $\mathrm{as}_{4}$, respectively. $\mathrm{Cp}, \mathrm{Cq}, \mathrm{Cr}$, and $\mathrm{Cs}$ are the concentrations of EMT, tenofovir, $\mathrm{COB}$, and ELV, respectively, in the diluted sample mixture. Using above equations $1,2,3$, and 4 the concentrations of the four drugs (EMT, TDF, COB, and ELV) in the sample mixture can be determined.

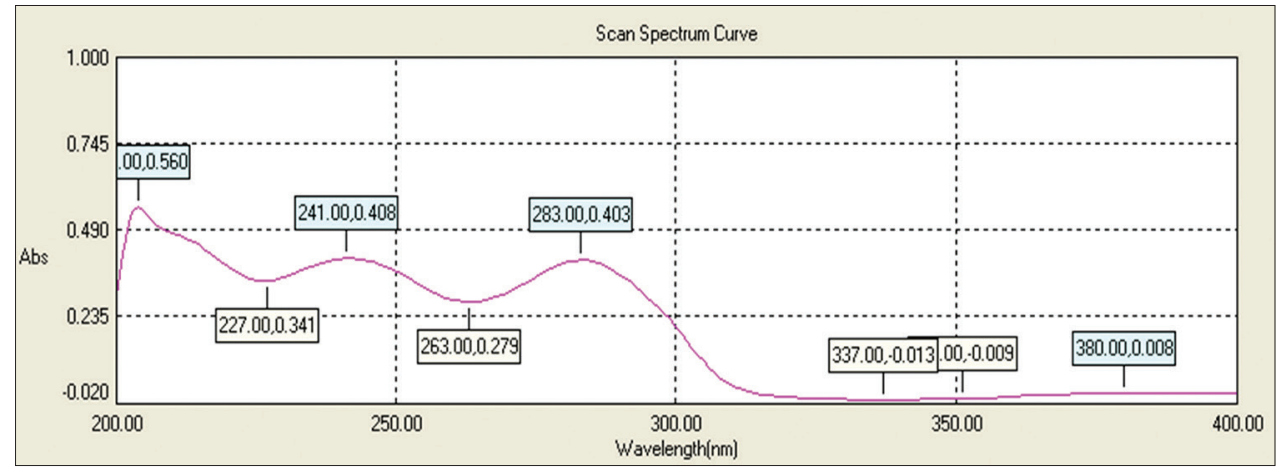

Fig. 5: Ultraviolet spectrum of emtricitabine reference standard

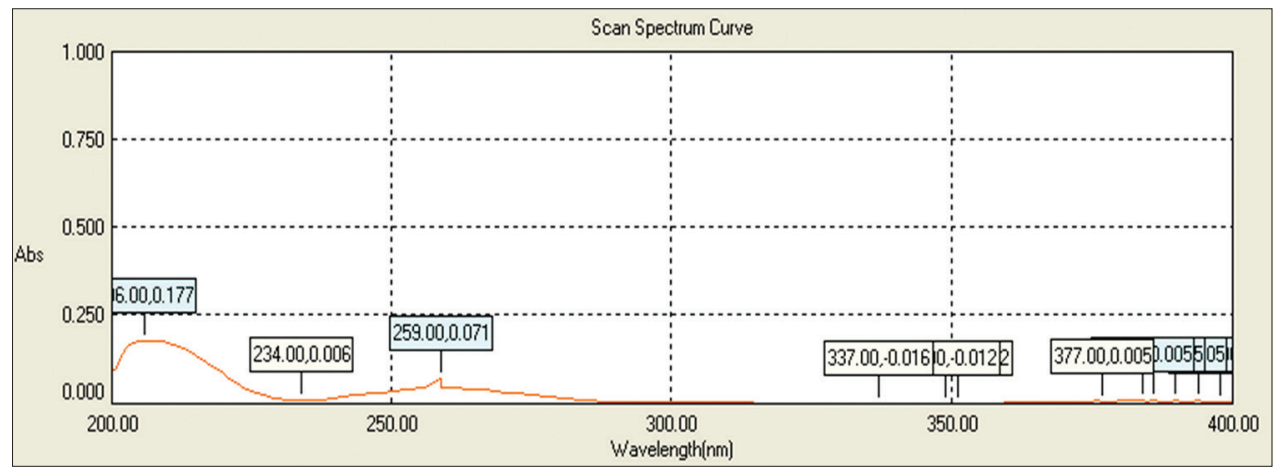

Fig. 6: Ultraviolet spectrum of tenofovir disoproxil fumarate reference standard

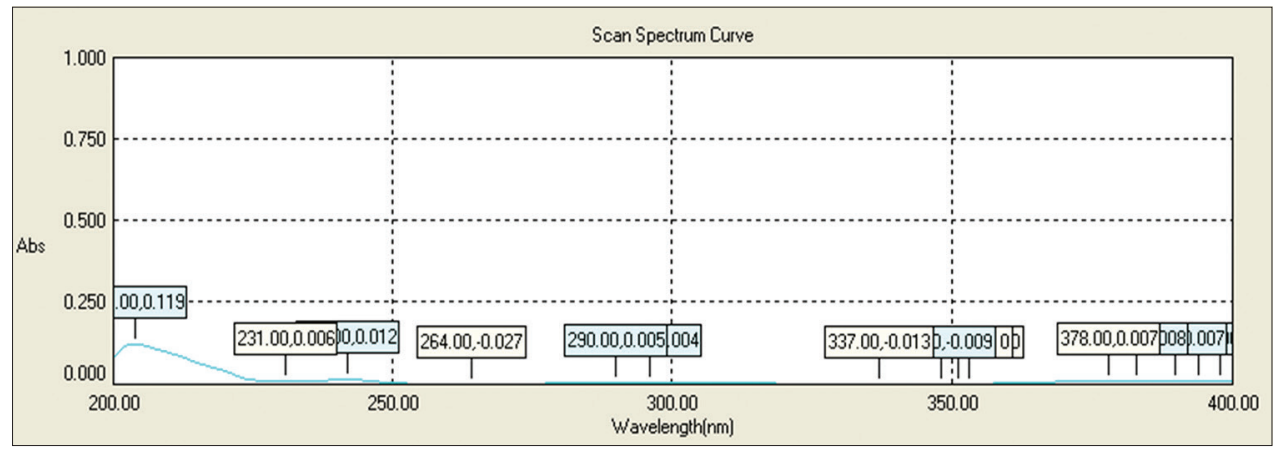

Fig. 7: Ultraviolet spectrum of cobicistat reference standard 


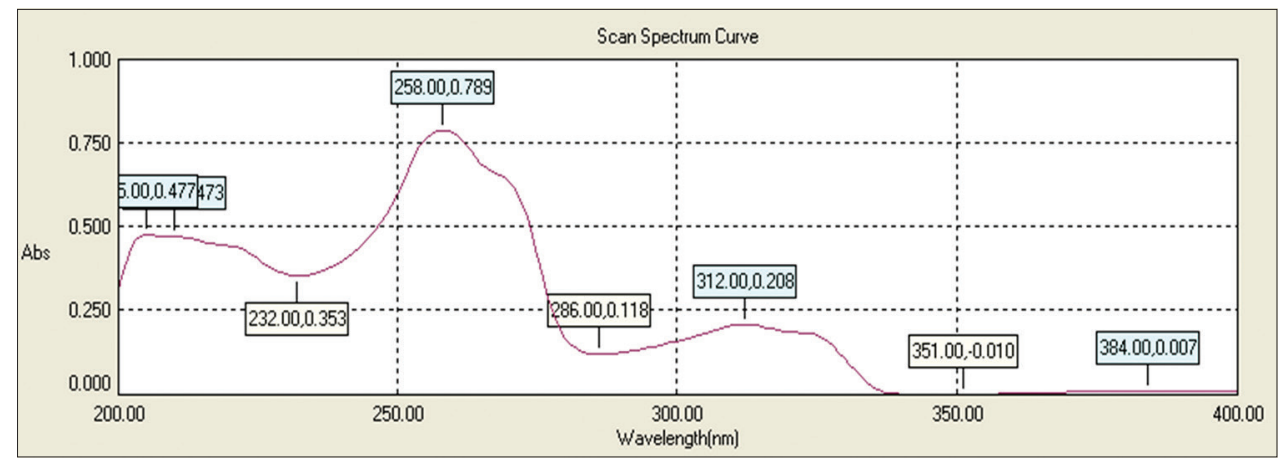

Fig. 8: Ultraviolet spectrum of elvitegravir reference standard

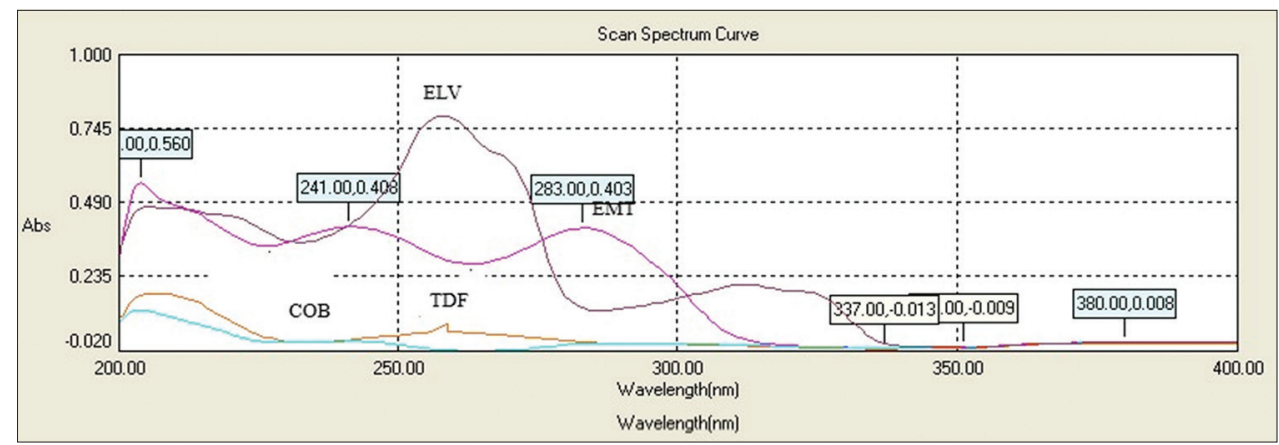

Fig. 9: Overlay ultraviolet spectrum of emtricitabine, tenofovir disoproxil fumarate, cobicistat, and elvitegravir standards (10 $\mu$ g/ml) in methanol

Table 1: Results of regression analysis of four drugs (EMT, TDF, COB, and ELV)

\begin{tabular}{lllll}
\hline Parameter & EMT & Tenofovir & COB & ELV \\
\hline$\lambda$ max $(\mathrm{nm})$ & 283 & 259 & 240 & 258 \\
Linearity & $4-24$ & $10-50$ & $10-120$ & $2-10$ \\
range $(\mu \mathrm{g} / \mathrm{ml})$ & & & & \\
Slope & 0.0348 & 0.0235 & 0.0061 & 0.0967 \\
$\begin{array}{l}\text { Intercept } \\
\text { Correlation }\end{array}$ & -0.0182 & 0.024 & 0.0166 & 0.0149 \\
coefficient $\left(\mathrm{R}^{2}\right)$ & 0.9999 & 0.9998 & 0.9996 & 0.9987 \\
LOD & & & & \\
LOQ & 0.87 & 1.39 & 0.78 & 1.14 \\
\hline
\end{tabular}

LOD: Limit of detection, LOQ: Limit of quantitation. EMT: Emtricitabine, TDF: Tenofovir disoproxil fumarate, COB: Cobicistat, ELV: Elvitegravir

Table 2: Linearity data of EMT

\begin{tabular}{ll}
\hline Concentration $(\boldsymbol{\mu g} / \mathbf{m l})$ & Absorbance \\
\hline 4 & 0.119 \\
8 & 0.265 \\
12 & 0.399 \\
16 & 0.535 \\
20 & 0.677 \\
24 & 0.819 \\
Mean & 0.469 \\
SD & 0.260 \\
Standard error & 0.0033 \\
\hline
\end{tabular}

EMT: Emtricitabine, SD: Standard deviation

Application of the Vierordt's method for pharmaceutical formulation [15] Sample preparation

Ten tablets of stribild were weighed to get the average weight and then ground. An amount of powder equivalent to about $200 \mathrm{mg}$ of EMT, $300 \mathrm{mg}$ of TDF, $150 \mathrm{mg}$ of COB, and $150 \mathrm{mg}$ of ELV into a $100 \mathrm{ml}$ clean dry volumetric flask, add methanol and sonicate to dissolve it completely and
Table 3: Linearity data of TDF

\begin{tabular}{ll}
\hline Concentration $(\boldsymbol{\mu g} / \mathrm{ml})$ & Absorbance \\
\hline 10 & 0.257 \\
20 & 0.498 \\
30 & 0.721 \\
40 & 0.968 \\
50 & 1.195 \\
Mean \pm SD & $0.7278 \pm 0.3709$ \\
Standard error & 0.0059 \\
\hline
\end{tabular}

TDF: Tenofovir disoproxil fumarate, SD: Standard deviation

Table 4: Linearity data of $\mathrm{COB}$

\begin{tabular}{ll}
\hline Concentration $(\boldsymbol{\mu g} / \mathbf{m l})$ & Absorbance \\
\hline 10 & 0.081 \\
20 & 0.135 \\
40 & 0.262 \\
60 & 0.395 \\
80 & 0.530 \\
100 & 0.668 \\
120 & 0.733 \\
Mean \pm SD & $0.3931 \pm 0.251$ \\
Standard error & 0.0203 \\
\hline
\end{tabular}

COB: Cobicistat, SD: Standard deviation

make the volume up to the mark with methanol (stock solution). Further pipette $5 \mathrm{ml}$ of the above stock solution into a $50 \mathrm{ml}$ volumetric flask and dilute up to the mark with diluent. The above solution was analyzed at $283 \mathrm{~nm}, 259 \mathrm{~nm}, 240 \mathrm{~nm}$, and $258 \mathrm{~nm}$ wavelengths and values of the absorbance were substituted in respective equations $1,2,3$, and 4 to obtain the concentration of EMT, TDF, COB, and ELV in the sample mixture.

\section{Forced degradation study at various stress conditions}

Forced degradation studies were performed on stock solutions of EMT, TDF, COB, and ELV individually to prove the stability indicating a property 
of the method. The stress conditions employed for degradation study included acid hydrolysis (with $5 \mathrm{ml}$ of $0.1 \mathrm{~N} \mathrm{HCl}$ ), base hydrolysis (with $5 \mathrm{ml}$ of $0.1 \mathrm{~N} \mathrm{NaOH}$ ), oxidation (with $5 \mathrm{ml}$ of $30 \% \mathrm{H}_{2} \mathrm{O}_{2}$ ), thermal (10 mg drug weighed individually and taken in Petri dishes and kept in hot air oven at $70^{\circ} \mathrm{C}$ ), and photostability (the stock solutions were exposed to sunlight for

Table 5: Linearity data of ELV

\begin{tabular}{ll}
\hline Concentration $(\boldsymbol{\mu g} / \mathbf{m l})$ & Absorbance \\
\hline 2 & 0.218 \\
4 & 0.398 \\
6 & 0.577 \\
8 & 0.795 \\
10 & 0.986 \\
Mean \pm SD & $0.5948 \pm 0.305$ \\
Standard error & 0.012 \\
\hline
\end{tabular}

ELV: Elvitegravir, SD: Standard deviation
$8 \mathrm{~h}$ on 3 consecutive days). The duration of time selected for degradation studies was $24 \mathrm{~h}$, and then the stock solutions were further diluted with methanol, and all the samples were analyzed in UV spectrophotometer along with their control samples [16].

\section{Validation of developed method}

The method was validated according to International Conference on Harmonization (ICH) guidelines to determine the linearity, limit of detection (LOD), limit of quantification (LOQ), precision, accuracy, ruggedness, and robustness of the method [17-24].

\section{RESULTS AND DISCUSSION}

Linearity

Linearity was evaluated by preparing the solutions having the concentration range of EMT $4-24 \mu \mathrm{g} / \mathrm{ml}$, TDF $10-50 \mu \mathrm{g} / \mathrm{ml}$, COB $10-120 \mu \mathrm{g} / \mathrm{ml}$, and ELV $2-10 \mu \mathrm{g} / \mathrm{ml}$. The calibration curves were obtained by plotting absorbance against concentration $(\mu \mathrm{g} / \mathrm{ml})$ and

Table 6: Method precision results for EMT, TDF, COB, and ELV

\begin{tabular}{|c|c|c|c|c|c|c|c|c|c|}
\hline \multirow[t]{2}{*}{ Drug name } & \multirow[t]{2}{*}{ Concentration $(\mu \mathrm{g} / \mathrm{ml})$} & \multicolumn{6}{|c|}{ Absorbances } & \multicolumn{2}{|l|}{ Absorbance } \\
\hline & & 1 & 2 & 3 & 4 & 5 & 6 & Mean \pm SD & \% RSD \\
\hline EMT & 10 & 0.399 & 0.397 & 0.398 & 0.396 & 0.395 & 0.395 & $0.396 \pm 0.001$ & 0.25 \\
\hline Tenofovir & 10 & 0.257 & 0.254 & 0.255 & 0.259 & 0.259 & 0.256 & $0.256 \pm 0.002$ & 0.78 \\
\hline $\mathrm{COB}$ & 10 & 0.083 & 0.084 & 0.084 & 0.085 & 0.083 & 0.083 & $0.083 \pm 0.0008$ & 0.99 \\
\hline ELV & 10 & 1.031 & 1.029 & 0.987 & 1.030 & 1.032 & 1.033 & $1.023 \pm 0.018$ & 1.02 \\
\hline
\end{tabular}

Conc.: Concentration. SD: Standard deviation, RSD: Relative standard deviation. EMT: Emtricitabine, TDF: Tenofovir disoproxil fumarate, COB: Cobicistat, ELV: Elvitegravir

Table 7: Intermediate precision, intraday ( $0 \mathrm{~h}$ and $8 \mathrm{~h}$ ) and interday (day 1 and day 2) results for EMT, TDF, COB, and ELV

\begin{tabular}{|c|c|c|c|}
\hline Drug name & Time interval & Absorbance mean \pm SD & \% RSD \\
\hline \multirow[t]{4}{*}{ EMT } & $0 \mathrm{~h}$ & $0.348 \pm 0.001$ & 0.28 \\
\hline & $8 \mathrm{~h}$ & $0.359 \pm 0.003$ & 0.83 \\
\hline & Day 1 & $0.339 \pm 0.004$ & 1.17 \\
\hline & Day 2 & $0.295 \pm 0.005$ & 1.69 \\
\hline \multirow[t]{4}{*}{ Tenofovir } & $0 \mathrm{~h}$ & $0.245 \pm 0.002$ & 0.81 \\
\hline & $8 \mathrm{~h}$ & $0.312 \pm 0.004$ & 1.21 \\
\hline & Day 1 & $0.296 \pm 0.002$ & 0.67 \\
\hline & Day 2 & $0.256 \pm 0.003$ & 1.17 \\
\hline \multirow[t]{4}{*}{ СOB } & $0 \mathrm{~h}$ & $0.089 \pm 0.0009$ & 1.01 \\
\hline & $8 \mathrm{~h}$ & $0.096 \pm 0.0007$ & 0.72 \\
\hline & Day 1 & $0.085 \pm 0.0008$ & 0.94 \\
\hline & Day 2 & $0.079 \pm 0.0006$ & 0.75 \\
\hline \multirow[t]{3}{*}{ ELV } & $0 \mathrm{~h}$ & $1.009 \pm 0.011$ & 1.09 \\
\hline & $8 \mathrm{~h}$ & $0.965 \pm 0.009$ & 0.93 \\
\hline & Day 1 & $0.985 \pm 0.009$ & 0.91 \\
\hline
\end{tabular}

SD: Standard deviation, RSD: Relative standard deviation. EMT: Emtricitabine, TDF: Tenofovir disoproxil fumarate, COB: Cobicistat, ELV: Elvitegravir

Table 8: Results of accuracy, \% Recovery studies for EMT, TDF, COB, and ELV

\begin{tabular}{|c|c|c|c|c|c|}
\hline $\begin{array}{l}\text { Drug } \\
\text { name }\end{array}$ & Concentration (\%) & Amount taken $(\mu \mathrm{g} / \mathrm{ml})$ & Amount spiked $(\mu \mathrm{g} / \mathrm{ml})$ & Amount recovered $(\mu \mathrm{g} / \mathrm{ml})$ & $\%$ Recovery \\
\hline \multirow[t]{3}{*}{ EMT } & 50 & 10 & 5 & 14.93 & 99.53 \\
\hline & 100 & 10 & 10 & 20.12 & 100.6 \\
\hline & 150 & 10 & 15 & 24.85 & 99.42 \\
\hline \multirow[t]{3}{*}{ Tenofovir } & 50 & 20 & 10 & 30.13 & 100.4 \\
\hline & 100 & 20 & 20 & 39.65 & 99.12 \\
\hline & 150 & 20 & 30 & 49.85 & 99.16 \\
\hline \multirow{2}{*}{$\mathrm{COB}$} & 100 & 50 & 50 & 101.32 & 101.32 \\
\hline & 150 & 50 & 75 & 125.68 & 100.54 \\
\hline \multirow[t]{3}{*}{ ELV } & 50 & 6 & 3 & 9.12 & 101.33 \\
\hline & 100 & 6 & 6 & 11.98 & 99.83 \\
\hline & 150 & 6 & 9 & 15.07 & 100.46 \\
\hline
\end{tabular}

EMT: Emtricitabine, TDF: Tenofovir disoproxil fumarate, COB: Cobicistat, ELV: Elvitegravir 
Table 9: Robustness studies (by changing the wavelength $\pm 1 \mathrm{~nm}$ )

\begin{tabular}{|c|c|c|c|c|}
\hline Drug name & Concentration $(\mu \mathrm{g} / \mathrm{ml})$ & Wavelength $\lambda \max ( \pm 1 \mathrm{~nm})$ & Absorbance mean \pm SD & $\%$ RSD \\
\hline \multirow[t]{2}{*}{ EMT } & 10 & 282 & $0.339 \pm 0.002$ & 0.58 \\
\hline & & 284 & $0.330 \pm 0.001$ & 0.30 \\
\hline \multirow[t]{2}{*}{ Tenofovir } & 10 & 258 & $0.217 \pm 0.003$ & 1.32 \\
\hline & & 260 & $0.272 \pm 0.004$ & 1.47 \\
\hline \multirow[t]{2}{*}{ COB } & 10 & 239 & $0.056 \pm 0.0005$ & 0.89 \\
\hline & & 241 & $0.122 \pm 0.0012$ & 0.98 \\
\hline \multirow[t]{2}{*}{ ELV } & 10 & 257 & $0.877 \pm 0.005$ & 0.57 \\
\hline & & 259 & $0.996 \pm 0.007$ & 0.70 \\
\hline
\end{tabular}

SD: Standard deviation, RSD: Relative standard deviation. EMT: Emtricitabine, COB: Cobicistat, ELV: Elvitegravir

Table 10: Ruggedness studies (by changing the analyst and instrument)

\begin{tabular}{|c|c|c|c|c|c|c|c|}
\hline $\begin{array}{l}\text { Drug } \\
\text { name }\end{array}$ & $\begin{array}{l}\text { Concentration } \\
(\mu \mathrm{g} / \mathrm{ml})\end{array}$ & $\begin{array}{l}\text { Parameter } \\
\text { (analyst) }\end{array}$ & $\begin{array}{l}\text { Absorbance } \\
\text { mean } \pm S D\end{array}$ & $\%$ RSD & Parameter (instrument) & Absorbance mean \pm SD & $\%$ RSD \\
\hline EMT & 10 & Analyst 1 & $0.335 \pm 0.003$ & 0.89 & Lab India T60 & $0.364 \pm 0.003$ & 0.82 \\
\hline \multirow[t]{2}{*}{ TDF } & 10 & Analyst 1 & $0.268 \pm 0.003$ & 1.11 & Lab India T60 & $0.279 \pm 0.002$ & 0.71 \\
\hline & & Analyst 2 & $0.264 \pm 0.004$ & 1.51 & Thermo scientific UV10 & $0.276 \pm 0.001$ & 0.36 \\
\hline \multirow[t]{2}{*}{$\mathrm{COB}$} & 10 & Analyst 1 & $0.059 \pm 0.0008$ & 1.35 & Lab India T60 & $0.061 \pm 0.0007$ & 1.14 \\
\hline & & Analyst 2 & $0.062 \pm 0.0007$ & 1.12 & Thermo scientific UV10 & $0.063 \pm 0.0006$ & 0.95 \\
\hline \multirow[t]{2}{*}{ ELV } & 10 & Analyst 1 & $0.912 \pm 0.002$ & 0.21 & Lab India T60 & $0.958 \pm 0.003$ & 0.31 \\
\hline & & Analyst 2 & $0.925 \pm 0.004$ & 0.43 & Thermo scientific UV10 & $0.949 \pm 0.005$ & 0.52 \\
\hline
\end{tabular}

Conc.: Concentration, SD: Standard deviation, RSD: Relative standard deviation. RSD: Relative standard deviation, EMT: Emtricitabine, TDF: Tenofovir disoproxil fumarate, COB: Cobicistat, ELV: Elvitegravir, UV: Ultraviolet

Table 11: Forced degradation results at various stress conditions

\begin{tabular}{llllllll}
\hline $\begin{array}{l}\text { Drug } \\
\text { name }\end{array}$ & Parameter & Control & $\begin{array}{l}\text { Acid } \\
\text { hydrolysis }\end{array}$ & $\begin{array}{l}\text { Alkali } \\
\text { hydrolysis }\end{array}$ & $\begin{array}{l}\text { Oxidation } \\
\text { (peroxide) }\end{array}$ & Thermal (hot air oven) & Photostability (sunlight) \\
\hline EMT & Absorbance & 0.336 & 0.321 & 0.231 & 0.329 & 0.315 & 0.326 \\
& \% Degradation & & 4.46 & 16.66 & 2.02 & 6.25 & 0.019 \\
Tenofovir & Absorbance & 0.265 & 0.016 & 0.219 & 0.241 & 0.246 \\
& \% Degradation & & 94 & 17.3 & 9.4 & 93 & 0.081 \\
COB & Absorbance & 0.083 & 0.081 & 0.079 & 0.0828 & 0.082 \\
& \% Degradation & & 3.2 & 4.9 & 0.2 & 2.5 & 0.926 \\
ELV & Absorbance & 0.928 & 0.927 & 0.914 & 0.912 & 0.9 \\
& \% Degradation & & 0.2 & 1.6 & 1.8 & 0.3 \\
\hline
\end{tabular}

EMT: Emtricitabine, COB: Cobicistat, ELV: Elvitegravir

Table 12: Absorptivity values of EMT, TDF, COB, and ELV at different wavelengths ( $\lambda$ max)

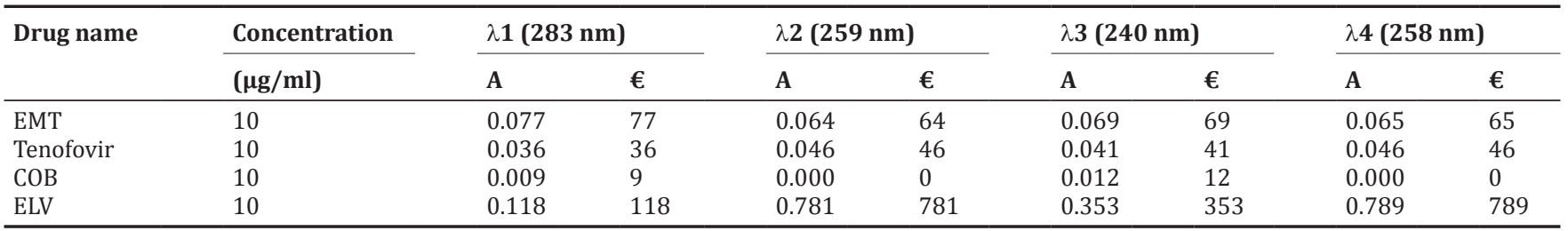

A=Absorbance, $€=$ Molar absorptivity, $\lambda=$ Wavelength. EMT: Emtricitabine, TDF: Tenofovir disoproxil fumarate, COB: Cobicistat, ELV: Elvitegravir

Table 13: Results of assay

\begin{tabular}{llll}
\hline Drug name & $\begin{array}{l}\text { Labeled } \\
\text { claim (mg) }\end{array}$ & Amount found (mg) & \% Purity \\
\hline EMT & 200 & 198.76 & 99.38 \\
Tenofovir & 300 & 303.21 & 101.07 \\
COB & 150 & 151.24 & 100.82 \\
ELV & 150 & 149.58 & 99.72 \\
\hline
\end{tabular}

EMT: Emtricitabine, COB: Cobicistat, ELV: Elvitegravir

are shown in Fig. 10-13. Standard deviation (SD), slope, intercept, and correlation coefficient $\left(\mathrm{R}^{2}\right)$ of the calibration curves were calculated to ascertain the linearity of the method and are reported in Table 1-5.

\section{LOD and LOQ}

The LOQ and LOD were based on the SD of the response and the slope of the constructed calibration curve, as described in ICH Guidelines Q2 (R1).

$\mathrm{LOD}=3.3 \times \sigma / \mathrm{S}$ and $\mathrm{LOQ}=10 \times \sigma / \mathrm{S}$

Where $\sigma=$ the SD of the response and $\mathrm{S}=$ slope of the calibration curve.

The LOD and LOQ values are reported in Table 1.

\section{Precision}

The precision of the assay was determined by repeatability (intraday) and intermediate precision (interday). Repeatability was evaluated 


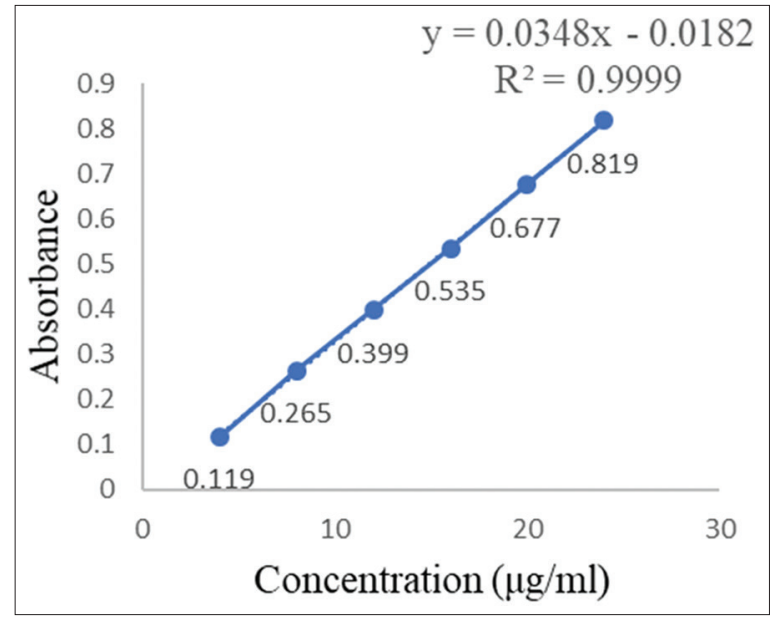

Fig. 10: Calibration curve for emtricitabine

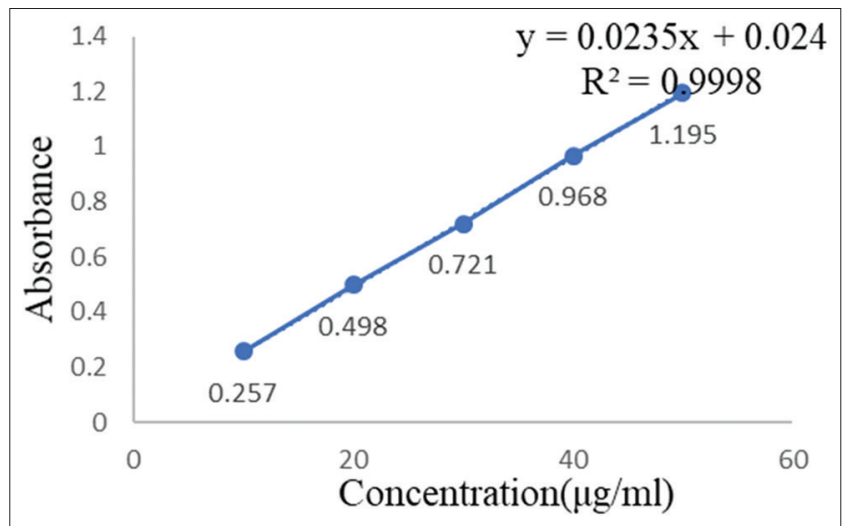

Fig. 11: Calibration curve for tenofovir disoproxil fumarate

by assaying samples, at same concentration on the same day. The intermediate precision was studied by comparing the assays on consecutive days. Six sample solutions $(\mathrm{n}=6)$ of fixed concentration $10 \mu \mathrm{g} / \mathrm{ml}$ of all the four drugs (EMT, TDF, COB, and ELV) were prepared and assayed. The results are reported in terms of relative SD (\% relative standard deviation [RSD]) in Tables 6 and 7. The \% RSD values are $<2$.

\section{Accuracy}

The accuracy of the proposed method was determined using recovery studies by spiking method. The recovery studies were carried out by adding different amounts $(50 \%, 100 \%$, and $150 \%)$ of the pure drug to the pre-analyzed formulation. The solutions were prepared in triplicates, and the \% recovery should be within the range of $98-102 \%$. The results are reported in Table 8.

\section{Robustness}

As per ICH norms, small but deliberate, variations of the UV method were determined by changing the wavelength by $\pm 1 \mathrm{~nm}$. The effect on absorbance was studied. The results are reported in terms of \% RSD in Table 9.

\section{Ruggedness}

Ruggedness was performed by two different analysts and two different instruments (Lab India T60 and thermo scientific UV10 UV-visible spectrophotometers), and the results of the study are given in Table 10 and $\%$ RSD obtained was $<2$ which is within the acceptance limits.

\section{Forced degradation studies}

Forced degradation studies were performed at various stress conditions and the $\%$ degradation was within the limits. The results obtained are shown in Table 11.

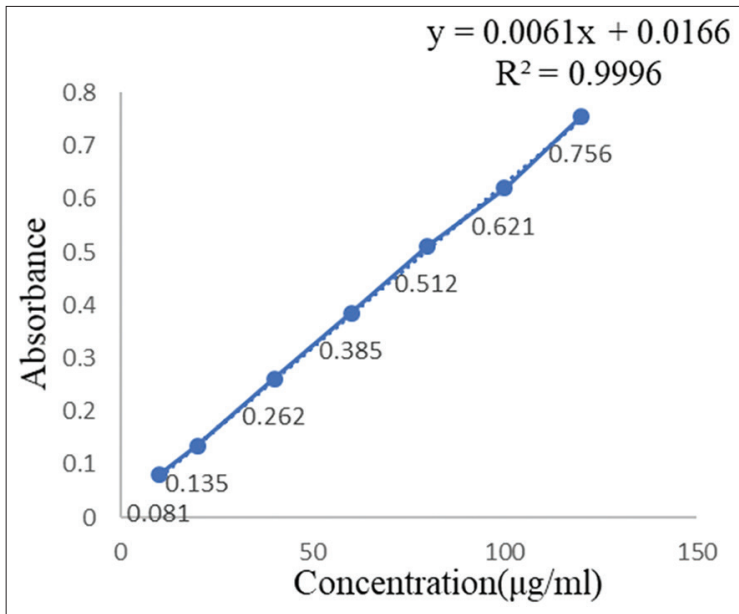

Fig. 12: Calibration curve for cobicistat

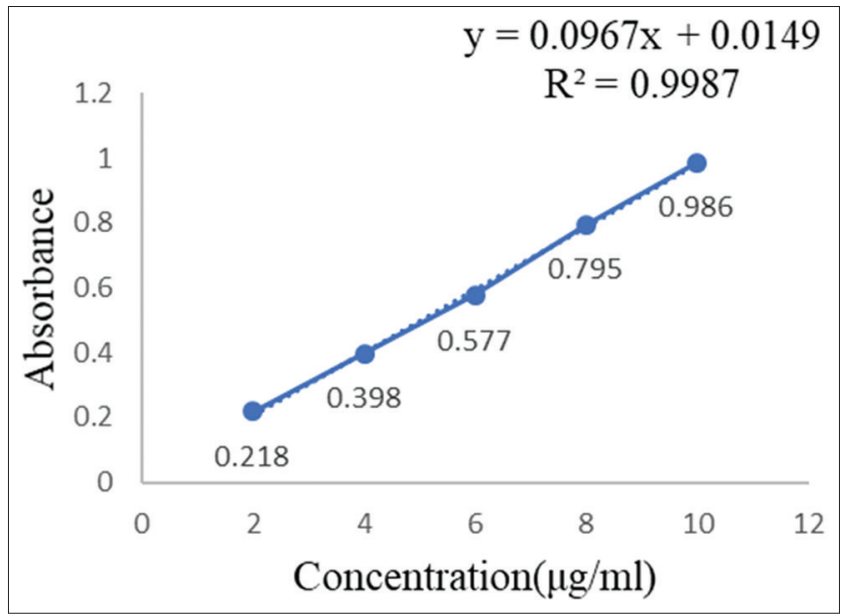

Fig. 13: Calibration curve for elvitegravir

Analysis of Pharmaceutical Dosage Form (Stribild Tablets)

The \% purity of EMT, tenofovir, COB, and ELV was 99.38, 101.07, 100.82, and 99.72 , respectively, obtained by simultaneous equation method and results are shown in Tables 12 and 13.

\section{CONCLUSION}

The Vierordt's method has been successfully applied for simultaneous determination of EMT, TDF, COB, and ELV in a mixture of sample solution (pharmaceutical dosage form) and the results obtained were validated and found to be accurate, precise, linear, rugged, and robust. Once the equations were constructed, the analysis required only measuring the absorbance values of the sample solution at the selected wavelengths followed by few simple calculations. Simultaneous equation method comparably noted to be very efficient in every aspect. Unlike highperformance liquid chromatography, using simultaneous equation method in UV spectroscopy, the data can be generated applying simple calculations. Hence, this method can be easily and conveniently adopted for routine quality control analysis of stribild tablets.

\section{ACKNOWLEDGMENTS}

The authors are thankful to University College of Pharmaceutical Sciences, Andhra University, Visakhapatnam, Andhra Pradesh, India, for providing facilities to carry out the research work.

\section{CONFLICT OF INTEREST}

The authors declare that there is no conflict of interests regarding the publication of this paper. 


\section{REFERENCES}

1. Sweetman SC, editor. Martindale - The Complete Drug Reference. $36^{\text {th }}$ ed., Vol. 1. London, UK: Pharmaceutical Press; 2009.

2. Gilead Sciences "New Drug Applications for Cobicistat and Elvitegravir for HIV Therapy Accepted by U.S. FDA”, April 21; 2014.

3. Aids info Drug Database. Elvitegravir/Cobicistat/Emtricitabine/ Tenofovir Disoproxil Fumarate. Available from: https://www.aidsinfo. nih.gov/drugs/507/stribild/0/patient.

4. Highlights of Prescribing Information. STRIBILD ${ }^{\circledR}$ (Elvitegravir, Cobicistat, Emtricitabine, Tenofovir Disoproxil Fumarate) Tablets, for oral use Initial U.S. Approval; 2012.

5. O’Neil MJ. The Merck Index-An Encyclopedia of Chemicals, Drugs, and Biological. $13^{\text {th }}$ ed. Whitehouse Station, NJ: Published by Merck Research Laboratories; 2001. p. 1631-2.

6. Kamal AH, El-Malla SF, Hammad SF. A review on UV spectrophotometric methods for simultaneous multicomponent analysis. Eur J Pharm Med Res 2016;3:348-60.

7. Elzanfaly ES, Saadn AS, Elaziz BA. A smart simple spectrophotometric method for simultaneous determination of binary mixtures. J Pharm Anal 2012;2:382-5.

8. Chaudhary J, Jain A, Saini V. Simultaneous estimation of multicomponent formulations by UV-visible spectroscopy: An overview. Int Res J Pharm 2011;2:81-3.

9. Soumya B, Kumar TM, Raghunandhan N. Simultaneous determination of tenofovir disoproxil fumarate and lamivudine by UV spectrophotometric method. Int J Pharm Pharm Sci Res 2012;2:9-15.

10. Himaja M, Kalpana J, Anbarasu C. Validated zero order and first order derivative spectrophotometric methods for in vitro analysis of tenofovir disoproxil fumarate tablets using azeotropic mixture. Int J Pharm Pharm Sci 2014;6:302-4.

11. AbdelHay MH, Gazy AA, Shaalan RA, Ashour HK. Simple spectrophotometric methods for determination of tenofovir fumarate and emtricitabine in bulk powder and in tablets. J Spectrosc 2013;2013:937409.

12. Ilango $K$, Sunitha PG. Development and validation of UV spectrophotometric methods for the simultaneous determination of emtricitabine and tenofovir in combined dosage form. J Pharm Res 2012;5:873-5.

13. Ghorpade SA, Sali MS, Kategaonkar AH, Patel DM, Choudhari VP, Kuchekar BS. Simultaneous determination of emtricitabine and tenofovir by area under curve and dual wavelength spectrophotometric method. J Chil Chem Soc 2010;55:115-7.

14. Choudhari VP, Parekar SR. Development and validation of UV-visible spectrophotometric baseline manipulation method for simultaneous quantitation of tenofovir disoproxil fumarate and emtricitabine in pharmaceutical dosage form. J Spectrosc 2013;2013:146580.

15. Venkatesan S, Kannappan N. Simultaneous spectrophotometric method for determination of emtricitabine and tenofovir disoproxil fumarate in three-component tablet formulation containing rilpivirine hydrochloride. Int Sch Res Notices 2014;2014:541727.

16. Blessy M, Patel RD, Prajapati PN, Agrawal YK. Development of forced degradation and stability indicating studies of drugs-A review. J Pharm Anal 2014;4:159-65.

17. Validation of Analytical Procedure. Text and Methodology. Edinburgh: Elsevier/Churchill Livingstone, European Medicines Agency; 1995. p. 229-44.

18. ICH Harmonized Tripartite Guideline. Validation of Analytical Procedures, Text and Methodology, Q2 (R1). Geneva, Switzerland: International Conference on Harmonization, IFPMA; 2005.

19. Pardhi SS, Aher KB, Bhavar GB, Chaudhari SR. Development and validation of UV spectrophotometric method for the estimation of elvitegravir (EVG) in bulk and pharmaceutical formulations. Int $\mathrm{J}$ Pharm Sci Res 2015;6:5.

20. Dhatkar D, Ahmad S, Shastry VM. Development and validation of UV-visible spectrophotometric method for estimation of emtricitabine and tenofovir in bulk and dosage form. Int $\mathrm{J}$ Pharm Pharm Res 2017:9:74-84.

21. Sri KV, Madhuri M, Jain GV. Multivariate UV-visible spectrophotometric method for the estimation of emtricitabine in bulk form. Int $\mathrm{J}$ Pharm Dev Technol 2015;5:89-93

22. Gnanarajan G, Gupta AK, Juyal V, Kumar P, Yadav PK, Kailash P. A validated method for development of tenofovir as API and tablet dosage forms by UV spectroscopy. J Young Pharm 2009; 1:351-3.

23. Kumar KA, Kannan K, Vetrichelvan T. Development and validation of emtricitabine and tenofovir disoproxil fumarate in pure and in fixed dose combination by UV spectrophotometry. Digest J Nanomater Biostruct 2011;6:1085-90.

24. Ravichandran V, Shalini S, Sundram KM, Rajak H. Validation of analytical methods - Strategies and importance. Int J Pharm Pharm Sci $2010 ; 2: 18-22$ 